\title{
Investigating the pre-service science teachers' conceptions about scientific inquiry research
}

\author{
Soraya Hamed* \\ Universidad de Sevilla, Departamento de Didáctica de las Ciencias Experimentales y Sociales, 41013 \\ Facultad de Ciencias de la Educación, Spain
}

\begin{abstract}
The following study presents the analysis of the conceptions of 40 future teachers when they are presented with a practical case related to the thermal properties of materials. This case is proposed as an experimental activity in which students must develop and reflect on the strategies of scientific research processes. For this, they are induced to explain: 1. The hypothesis from which they start to respond to the predetermined problem, 2. The experimental design to address it, 3 . The results and 4 . The conclusions obtained. The results indicate the existence of two tendencies, a majority related to a common sense thinking and another more counter-intuitive and scientific to explain natural phenomena.
\end{abstract}

\section{Context, objective and theoretical framework}

The current reforms in scientific education emphasize the importance of developing an informed understanding of science, its nature and the processes that generate it (that is, scientific research) as fundamental elements for the scientific literacy of citizens $[1,2,3]$. Therefore, understanding its nature and the methods that generate it are essential for making appropriate scientific decisions in the social and personal sphere [4]. These authors suggest the relevance of the Nature of Science (NOS) and Scientific Research (SI) as elements that are related and interact in an important way. Focusing on scientific research, it is known that students and science teachers do not have sophisticated knowledge about the nature of such practice $[5,6,4]$. One of the reasons is due to the distorted vision that we have about it [7]. The reasons can be diverse (the information provided by the media, the education received, among others). In addition, there are very few studies that systematically evaluate conceptions about this component [8].

The study we present is developed in the context of a teacher training course to learn to teach science, whose educational reference is school research $[9,10]$ and is based on research of fundamental professional problems (What is Science, what is its nature, how scientific knowledge is built, what Science to teach, how to do it, etc.). In this line, we have selected an activity that has been used and detailed by some authors [11] to study the thermal properties of certain materials. In our case, we intend to examine the conceptions that future science teachers have to develop appropriate training strategies and adjusted to

\footnotetext{
* Corresponding author: sha@us.es
} 
the characteristics of these conceptions. To that end, we have considered curricular reforms and current research as a frame of reference $[3,12]$.

\section{Methods}

The study is developed during the academic year 2017-18 in a class corresponding to the 2nd year of Primary Education Degree in the subject of Experimental Science Didactics at the University of Seville. It is a group of 40 students whose average age is in their $20 \mathrm{~s}$, although the range is between 18 and 37 years old. The majority of students are women (62.5\% of the class). They were grouped into working groups of between 3 and 5 participants each to be able to address the case. For the study, qualitative research was carried out framed in a descriptive and interpretative paradigm [13] to examine the understanding of future science teachers of the University of Seville.

In relation to the information collection and analysis instrument we use the following case study: After an air accident we made an emergency landing in the Sahara desert and the flight attendants told us that the plane carried some very valuable and important medicines that we have to protect at all costs while we wait for the rescue. For this we have wool cloths and metal pots. How do you think we can get the medicines to stay as cold as possible? Wrapping them with wool? Putting them in the pots? else? Once exposed, students should explain and explain to the rest of the classmates the hypotheses suggested by this case. The information is collected in your personal report of the activity. Next, they must design the test (s) they consider necessary to verify their hypothesis. Afterwards, they must detail the results and conclusions obtained before and after the discussion among the classmates. In total, we have 40 personal reports on the experience. With respect to the analysis of information, we have identified and classified units of information relevant to the construction of propositions that summarize in an organized manner the aspects investigated "Hypothesis (H), Experimental Design, (D) Results and Conclusions (C)". The categorization has been made according to the degree of complexity of the answers. That is, the minimum value of 1 would correspond to a level of formulation of knowledge more naive or less sophisticated and the value 4, the level of greater complexity or reference. In this line we have for the category "Hypothesis" the levels H1, H2, H3 and H4; for the category "Experimental design" (D) we have the levels D1, D2, D3 and D4 and for the category "Results-Conclusions" we have the levels C1, C2, C3 and C4. Levels 2 and 3 correspond to intermediate or transitional values between extreme levels 1 and 4. Finally, the categories have been validated through triangulation processes among several researchers. Two researchers have performed the analysis of the responses separately so that at least $80 \%$ agreement is reached. In addition, to manage this task, we have helped with the ATLAS.ti program, version 8.

\section{Results and conclusions}

\subsection{Hypothesis $(\mathrm{H})$}

With regard to this aspect, we detect that the majority of future teachers (65\%) believe in the use of metal to better preserve medicines (H1). The reasons they provide are related to the behavior produced by the materials (metal and wool) when contacting the ice. In the 
case of metal, it would "cool" with ice and, in the case of wool, it would "heat" it. That is to say, in a more or less explicit way, they carry out explanations based on the sensory perception of the phenomena (macroscopic description). Within this group of students, we identified that $57.5 \%$ have a somewhat more elaborate vision when trying to combine different materials (metal, wool, etc.) to keep medicines cold (H2). However, metal is still the material chosen as the most suitable to achieve it. On the other hand, we found that $35 \%$ of students choose either only wool $(17.5 \%)$ or the combination of this with other materials $(17.5 \%)$ as appropriate, providing scientific arguments ( $\mathrm{H} 3$ and $\mathrm{H} 4$, respectively).

\subsection{Experimental design (D)}

Regarding the experimental design, we identified a large group of students (55\%) who performed a single test to test their hypothesis. Among which, $40 \%$ use the combination Ice + Metal + Wool -HML- (D1) and 15\% the combination Ice + Wool + Metal HLM - (D2). On the other hand, we detected another group (45\%) that performs more than one experimental design to verify their hypothesis. On the one hand, $42.5 \%$ of the students use two designs in different ways: ice + (Ice + Wool + Metal + Wool) $-\mathrm{H}+$ HLML-; (Ice + Wool $)+($ Ice + Metal $)-H L+$ HM- and Ice + Wool + (Ice + Wool + Metal $)-H L+$ HLM(D3) and 5\% of students design more than two tests, one of them using control group (D4).

\subsection{Results and conclusions (C)}

Regarding this category, $22.5 \%$ of the students express their agreement to the use of metal as a preservative material for the drugs (they accept their starting hypothesis) (C1), despite the results obtained in the experimentation. In this case, it uses a single experimental design ("the medicine / ice inside the metal bucket"). However, after the discussion among the members of the group, they explain the need to use different methods and more resources to better test their hypothesis. In addition, $40 \%$ accept either the metal and the wool as conservative materials of the medicines / ice or else they reject the metal and accept the wool as a consequence of the discussion of the results obtained (C2). In this case, the experimental design is somewhat more elaborate because it includes more materials or the choice of a different material ("the ice in the saucepan and the latter wrapped in wool" or "only the wool"). However, the conclusions are made without testing experimentally with the contrast of different tests. On the other hand, 37.5\% of students accept wool as the most appropriate material for the conservation of medicines. For this, they provide scientific arguments, experimentally verified by carrying out different tests and establishing conclusions in coherence with them. Therefore, we observe that for all the categories ("Hypothesis", "Experimental design" and "Results-Conclusions"), the majority of students (around 50\%) are between levels 1 and 2 in terms of formulation of knowledge refers to each one of them.

According to this, we detected that most of the future teachers $(65 \%)$ believe in the usefulness of metal to better preserve medicines, although in some equipment it is used in combination with other materials ( $\mathrm{H} 1$ and $\mathrm{H} 2$ ). In addition, $55 \%$ of students believe that with the completion of a single test, it would suffice to check their hypothesis (D1 and D2). We also detected that $42.5 \%$ of students establish incongruent conclusions according to the experimental design and the results obtained $(\mathrm{C} 1$ and $\mathrm{C} 2)$. On the other hand, we identify 
that $35 \%$ of students choose wool because it is a good thermal insulator, rejecting metal as the conductive material of thermal energy ( $\mathrm{H} 3$ and $\mathrm{H} 4$ ). To reach these conclusions, $45 \%$ make and contrast different tests (D3 and D4), with 37.5\% of the students discussing and arguing scientifically the results obtained (C3 and $\mathrm{C} 4)$. It seems, therefore, that there is a majority group of future teachers who present a commonsense thinking in front of another group that presents a counter-intuitive and scientific thinking [14].

\section{References}

1. American Association for the Advancement of Science, Benchmarks for science literacy. New York, NY: Oxford University Press. (1993)

2. National Research Council, National science education standards. Washington, DC: National Academic Press. (1996)

3. M. Rocard, P. Csermely, D. Jorde, D. Lenzen, H. Walwerg Henriksson, V. Hemmo, Science Education Now: A Renewed Pedagogy for the Future of Europe. European Commission. Community Research, (2007)

4. N.G. Lederman, J.S. Lederman, A. Antink, Nature of science and scientific inquiry as contexts for the learning of science and achievement of scientific literacy. International Journal of Education in Mathematics, Science and Technology, 1(3), 138-147, (2013)

5. B. Schwartz, A. Ward, J. Monterosso, S. Lyubomirsky, K. White, D. R. Lehman, Maximizing versus satisficing: Happiness is a matter of choice. Journal of Personality and Social Psychology, 83(5), 1178-1197, (2002)

6. N.G. Lederman, J.S. Lederman, Revising Instruction to Teach Nature of Science. The Science Teacher, 71 (9): 36-39, (2004).

7. N. G. Lederman, Nature of science: Past, present, and future. In Handbook of research in science education, Edited by: Abell, S. K. and Lederman, N. G. Englewood cliffs, NJ: Erlbaum Publishers, (2007)

8. D. K. Capps, B. A. Crawford, M. A. Constas, A review of empirical literature on inquiry professional development: alignment with best practices and a critique of the findings. Journal of Science Teacher Education, 23, 291-318, (2012)

9. R. Porlán, R. Martín del Pozo, A., Rivero, J. Harres, P. Azcárate, M. Pizzato, El cambio del profesorado de ciencias I: Marco teórico y formativo, Enseñanza de las Ciencias, 28(1), 31-46, (2010)

10. Rivero, A., Martín del Pozo, R., Solís, E., Azcárate, P., Porlán, R., (2017) Cambio del conocimiento sobre la enseñanza de las ciencias de futuros maestros. Enseñanza de las Ciencias, 35 (1), pp. 29-52.

11. M.R. Ariza, D. Aguirre, A. Quesada, A.M. Abril, F.J. García, Lana o metal? Una propuesta de aprendizaje por indagación para el estudio de las propiedades térmicas de materiales comunes. Revista Electrónica de Enseñanza de las Ciencias, 15(2), 297-311, (2016)

12. J. S. Lederman, N. G. Lederman, S. A. Bartos, S. L. Bartels, A. A. Meyer, R. S. Schwartz, Meaningful assessment of learners' understandings about scientific inquiryThe views about scientific inquiry (VASI) questionnaire. Journal of Research in Science Teaching, 51(1), 65-83, (2014)

13. J.W. Creswell, Qualitative Inquiry \& Research Design: Choosing Among the Five Approaches. Thousand Oaks, CA: SAGE Publications, Inc. (pp. 77-83), (2013).

14. C. H. Yu, J. M. Cole, Friend or Foe? Common Sense in Science Education from the Perspective of History and Philosophy of Science, British Journal of Education, Society \& Behavioural Science, 4(5), 673-690, (2014) 